answerable. As judged by the small number of overt nuclear weapons states (only five plus India), the non-proliferation regime has worked far better than the Cassandras of the 1950 s had predicted. But judging from the existence of 'threshold' states - Pakistan, Israel, South Africa - we may be premature in this assessment. Additional measures, beyond the existing regime, ought to be considered: Scheinman offers us several, without advocating any of them very strongly.

Such measures might include proscription of reprocessing except under IAEA supervision; sequestering of plutonium, either in centralized storage, or in unprocessed fuel in supervised waste repositories; and a halt to vertical proliferation, culminating in a comprehensive test ban (CTB). The first of these measures may come into being in many nuclear power systems simply because reprocessing is too expensive; the second, which in a way captures some of the flavour of the original Eisenhower Atoms-for-Peace proposal, continues to receive sporadic support. The CTB, which some regard as the talisman that will end the spectre of proliferation (and which I strongly support), may be closer at hand, in the wake of the INF Treaty, than was conceivable at the time Scheinman wrote his book.

Can we, then, have nuclear power without proliferation, as nuclear proponents aver? Or must the world eventually forego nuclear power because proliferation is inevitably the unwanted bastard of fission? Professor Scheinman takes the optimistic view - that nuclear proliferation need not be the inevitable consequence of nuclear power provided the non-proliferation regime, and the IAEA, continue, little-by-little, to be strengthened. Whether additional states will 'go nuclear' by routes that do not require power plants and that circumvent the jurisdiction of IAEA, or of any international body for that matter, remains, and will always remain, an open, political question.

Alvin M. Weinberg, Institute for Energy Analysis, PO Box 117, Oak Ridge, Tennessee 37830, USA, is a former Director of Oak Ridge National Laboratory. With John Barkenbus, he is co-editor of The Nuclear Connection: A Reassessment of Nuclear Power and Nuclear Proliferation (Paragon House Press, 1987).

\section{Why do they do it?}

\section{Michael Bulmer}

The Evolution of Sex and its Consequences. Edited by S.C. Stearns. Birkhäuser:1987. Pp.403. SwFr.80, \$59.50.

The Evolution of Sex: An Examination of Current Ideas. Edited by Richard E. Michod and Bruce R. Levin. Sinauer Blackwell Scientific: 1988. Pp.342. Hbk $\$ 55 ; p b k \$ 29.95$. In the $U K p b k £ 23, h b k$ price yet to be set.

SEX is the big problem in evolutionary biology, the one we should all like to solve. Sexual reproduction has two clear disadvantages. First, recombination, its main consequence, breaks up coadapted gene complexes, which must be a bad thing in a constant environment. Second, there is the two-fold cost of sex. In anisogamous species with no paternal care of the young, a female who produces only female offspring parthenogenetically has a two-fold advantage over a sexual female who produces equal numbers of male and female offspring. There is some verbal disagreement whether this should be attributed to the cost of producing useless males or to the cost of genome dilution by meiosis and syngamy, but its reality is beyond doubt.

Why then do so many plants and animals do it? The fact that recombination breaks up gene complexes suggests that it can only be advantageous in a variable environment, but how can the advantage be large enough to outweigh the two-fold cost? This intriguing question has challenged theorists to produce an explanation and experimentalists to measure the relevant costs and benefits.

These two multi-author reviews are complementary, with remarkably little overlap either in authorship or coverage. The book edited by Stearns is rather broad in its scope, with chapters on the evolution of mating types and anisogamy, the costs of sex, sex-determining mechanisms, sex ratio and sex-allocation theory, and sexual selection in animals and plants, organized around a central core which discusses the leading hypotheses for the evolutionary maintenance of sex and the evidence for and against them.

I enjoyed most of these contributions, particularly those dealing with the empirical evidence. Bierzychudek reviews experimental tests of the advantage of sexual over asexual progeny, mostly the work of Antonovics and his students on the grass Anthoxanthum in which a substantial advantage has been found for sexual progeny. A criticism of this work is that the asexual progeny are obtained from vegetatively produced tillers which are subject to parental contamination; to avoid this problem Bierzychudek is currently working with Antennaria which produces both sexual and asexual (apomictic) seed.

Hebert reviews the comparative evidence about the genetics of cyclical parthenogens, such as aphids and Daphnia, which throws light both on the consequences of going asexual for a few genera- tions and on the evolution of cyclical parthenogenesis. Cyclical parthenogens are often quoted as showing that there must be a short-term advantage for sex, because they could easily become obligate parthenogens. Hebert disputes this argument and concludes that "asexuality originates as a product of internal genetic factors rather than as a response to selection pressures imposed by the environment"; I doubt however whether this conclusion would stand up to theoretical analysis. Gouyon and Couvet review data on the fecundity of females in gynodioecious plants, such as thyme, in which females and hermaphrodites coexist, and discuss the evolutionary maintenance of this condition.

The book edited by Michod and Levin concentrates in greater depth on the central problem of the evolutionary maintenance of sex. It gains breadth by examining a diversity of hypotheses, and by its extensive consideration of the molecular basis of recombination. Two lucid chapters by Felsenstein and Maynard Smith review the orthodox views on the evolution of recombination, while Seger and Hamilton discuss the front-running 'Red Queen' model in which sex is regarded as an adaptation in the coevolutionary battle between hosts and their parasites.

In contrast, Bernstein et al. regard recombination as an adaptation for DNA repair rather than for generating variability, and Holliday presents a variant of this idea based on the maintenance of the correct pattern of DNA methylation in the germ line; I found these chapters stimulating but unconvincing. Hickey and Rose present the even more way-out idea that the function of sex is to facilitate the horizontal transfer of parasitic DNA. There is a thought-provoking chapter by Levin on the evolution of sex in bacteria.

In summary, Stearns's book is strong on the empirical evidence, Michod and Levin's on the competing theories for the evolutionary maintenance of sex. Where do they leave us? Felsenstein is cynical:

This year, the sex crisis seems to have returned What has happened? Has a new source of data or a new kind of experiment been discovered that will help us resolve the controversies? . . . No. . . . The problem has simply flared up again and will probably gutter out after a while. Biologists will once again all become convinced that they know the answer, but once again there will be no unanimity as to what the answer turned out to be.

I disagree with this assessment. These two books, taken together, show that there is now much better understanding of the theoretical possibilities, and that experiments to distinguish between them are being done.

Michael Bulmer is a Lecturer in the Department of Biomathematics, University of Oxford, Oxford $O X I 3 U B, U K$. 